\title{
Oficina IN virtual com estudantes no ingresso ao ensino superior: Espaço dialógico em tempos de pandemia
}

\author{
Maria Angélica de Moura Buenoํㅡㄹ Lauren Machado Pinto² Maria Rita \\ de Assis Cesar ${ }^{3}$ Júlio Gomes ${ }^{4}$
}

\author{
1Unidade de Apoio Psicossocial da Universidade Federal do Paraná, Brasil | uaps@ufpr.br: \\ 13angelbueno@gmail.com |https://orcid.org/0000-0002-4185-6070 \\ Unidade de Apoio Psicossocial da Universidade Federal do Paraná, Brasil \\ lauren.machadopinto@gmail.com | https://orcid.org/0000-0002-3103-3206 \\ ${ }^{3}$ Pró-Reitoria de Assuntos Estudantis da Universidade Federal do Paraná, \\ Brasil | prae@ufpr.br; mritacesar@yahoo.com.br | https://orcid.org/0000-0002-5843-2899 \\ ${ }^{4}$ Pró-Reitoria de Graduação e Educação Profissional da Universidade Federal do Paraná, \\ Brasil | copap@ufpr.br | https://orcid.org/0000-0003-0746-9875
}

Resumo: Introdução: A Assistência Estudantil se constitui um campo de Política Pública com foco na Inclusão e Permanência de estudantes nas Instituições Federais de Ensino Superior, com ações em eixos de auxílio monetário e atendimento psicossocial. Desde o início da pandemia em 2020, a Oficina IN como uma das ações do projeto de extensão ao estudante ingressante (IN) em uma Universidade Pública Federal, promoveu ações de encontros coletivos síncronos em subtemas temáticos ao universo estudantil calouro. Objetivos, Métodos: O Projeto de Extensão IN, como um dos eixos de atendimento psicossocial, possui por objetivo investigar e prevenir sinais de vulnerabilidade sócioemocional inerentes à saúde mental no meio social, na garantia de inclusão e permanência universitária, em especial, de grupos sociais vulneráveis. Tensionamos apresentar a experiência do desenvolvimento dos encontros nas oficinas virtuais e análise dos Diários de campo semanais, considerando a análise dos impactos destas atividades no cotidiano dos estudantes. No ato do registo acadêmico a equipe do projeto aplicou um formulário para identificação das condições psicossociais dos estudantes e redes sociais de suporte entre os ingressos. Resultados: Ao longo do projeto de extensão no ano de 2020 sucedeu 32 encontros dentre 437 convites virtuais encaminhados, atingindo a adesão de participação voluntária de 62 estudantes ingressos nas Oficinas IN virtuais. Em avaliação qualitativa, segundo a leitura exaustiva do material registrado no Diário de Campo pelos bolsistas extensionistas do projeto IN, obtevese as categorias de Análise de Conteúdo nos eixos de discussão como: senso de pertença social, sentimentos de vulnerabilidade, ambiente virtual EaD na Educação e rede social de suporte. Conclusões: As oficinas promoveram estratégia de acolhimento; estabelecimento de vínculos e fortalecimento de redes sociais de suporte; protagonismo acadêmico em prevenção da saúde mental universitária. Configura-se como uma ação efetiva em plano contínuo de política pública em Inclusão e Permanência universitária.

Palavras-chave: Estudantes; Ensino Superior; Oficina; Virtual; Pandemia.

Virtual IN Workshop with Students Entering Higher Education: Dialogical Space in Time of Coronavirus Infection

Abstract: Student Assistance is a field in Public Politics that focuses on students' Inclusion and Permanence at the Federal Institutions of Higher Education, with actions on monetary and psychosocial aid. Since the beginning of the 2020 pandemic, IN workshop, as one of the actions of the extension project to the incoming student (IN) in a Federal Public University, has promoted synchronous colective meetings in subthemes related to the freshman student's universe. Objectives, Methods: The IN Extension Project, as one of its psychosocial care axes, aims to investigate and prevent signs of socioemotional vulnerability inherent to mental health in the social environment, in guaranteeing inclusion and university permanence, in particular, of vulnerable social groups. We intend to present the experience of the development of the meetings in the virtual workshops and the analysis of weekly field journals, considering the impact of these activites in the students' routines. At the time of the academic registry the project's team applied a form aiming the identification of psychosocial conditions of incoming students and social support networks between them. Results: Throughout the extension project in 2020, 32 meetings took place among 437 virtual invitations sent, reaching the voluntary participation of 62 students enrolled in the IN Virtual Workshops. In a qualitative evaluation, according to the exhaustive reading of the material registered in the Diário de Campo by the extension scholarship holders of the IN project, the Content Analysis categories were obtained in the discussion axes such as: sense of social belonging, feelings of vulnerability, virtual distance education in Education and social support network. Conclusions: The workshops promoted a welcoming strategy; establishing links and strengthening social support networks; academic leadership in the prevention of university mental health. It is configured as an effective action in a continuous public policy plan in Inclusion and University permanence.

Keywords: Students; Higher Education; Workshop; Virtual; Pandemics. 


\section{Inclusão e Permanência na Educação superior}

A educação superior numa universidade pública considera por missão o atendimento a comunidade externa mediante a atenção ao tripé ensino, pesquisa e extensão. Neste caminho, o Projeto direcionado ao conhecimento dos estudantes ingressantes, institucionalmente denominado (IN), visa contemplar desde 2019 uma abordagem integral na formação humana, digna e cidadã durante o período de Inclusão, Permanência e convivência social.

A aceleração da digitalização das instituições se deu à covid-19 pelo simples fato de o isolamento social ter obrigado o mundo a se adaptar às formas digitais de trabalhar, ensinar, aprender e interagir. Uma questão a se pontuar é a desigualdade gigante entre os sistemas públicos e privados da educação superior e a própria distância social entre as famílias dos estudantes. E o fato inquestionável de muitos estudantes das universidades públicas sequer ter acesso à internet. $\mathrm{O}$ isolamento criou novos hábitos $\mathrm{e}$ comportamentos, tanto nas famílias, quanto nas instituições de ensino, que estão revendo uma série de processos, estruturas e metodologias. Oliveira, M. L. (2011) aponta a formação de professores no ensino em suas diversas etapas, incluindo a universitária, notadamente ao ensino especializado às necessidades especiais em Educação Inclusiva:

A vocação primária da universidade é o ensino, a formação de recursos humanos, e, no caso das faculdades ou departamentos de Educação, a formação de professores. Este é, sem dúvida, o aspecto determinante para a efetivação de uma política de inclusão educacional, a atuação direta na formação inicial de professores, visto que esses profissionais vão atuar diretamente com estudantes portadores de NEE's (p.101).

O projeto de extensão desenvolve-se numa Pró-reitoria de Assuntos Estudantis numa universidade pública federal, sendo que a importância do projeto vai além da assistência ao sofrimento psíquico. As Oficinas IN abre as portas para uma ação sobre o impacto que a atividade com calouros pode causar. Isso permite que coletemos mais informações e dados sobre esse tipo de abordagem e auxiliar estudantes e seu grupo social entorno quanto a sinais como a ansiedade, irritabilidade e depressão conectados a concepção de saúde mental. Durante 2020 teve adesão de 583 estudantes INgressos no cadastro geral, referente a Fase I do projeto de extensão.

\subsection{Estudante (IN)gresso na Universidade Pública}

O projeto IN faz parte das ações em Assistência Estudantil da universidade pública federal em garantir Permanência cidadã no período acadêmico com bolsa auxílio de benefícios econômicos e em equipe de apoio psicossocial. Díaz-Camargo (2020) aponta a sobrevalência essencial da atenção essencial aos aspectos afetivo-emocionais da política pública, em comparação aos econômicos:

[...] la dimensión económica no se mostró significativamente relacionada con la permanencia en la muestra estudiada. Por el contrario, este estudio apoya el argumento que a permanencia depende de manera importante del bienestar del estudiante donde se contempla la salud física y mental, seguida de otras características personales y situacionales que rodean al estudiante (p.9).

Neste cenário em 2020, resultou re-edição na continuidade do Projeto IN em realização da fase I de aplicação de formulário de dados psicossociais aos estudantes ingressos na universidade, que denominamos (IN). Conforme metodologia, constitui Pesquisa Participante exploratória no convite de participação voluntária no momento do Registro Acadêmico. 
Consta de 28 questões objetivas de múltipla escolha e 1 questão aberta subjetiva, aberta quanto à expectativa de manutenção da permanência e preservação de qualidade de vida no processo universitário. Nivelou-se a 583 participações, equiparando a $11,25 \%$ da população geral de estudantes calouros INgressos.

A fase II compreendeu etapa Diagnóstica de análise do material de levantamento dos formulários elaborada em conjunto com a Fase III de intervenção nas Oficinas virtuais on-line com participação de estudantes extensionistas do curso de Psicologia e de Tecnologia em Desenvolvimento de Sistemas em cumprimento às medidas de prevenção do Ministério da Saúde de emergência de saúde pública decorrente da SARSCoV-2.

\subsection{A Virtualidade na Educação em Tempos de Pandemia}

Em decorrência da pandemia, o período curricular inaugurou um novo normal em nova sistematização de metodologia das Oficinas para continuidade de recepção aos estudantes (IN)gressos. Tornou-se oportunidade de convivência virtual entre os estudantes calouros no Tema Inclusão e Permanência universitária saudável num espaço de diálogo virtual interativo semanal na estruturação de re-pensar educação em tempos de distanciamento social imperativo. Santana et al. (2018) exploram a enorme importância da capacitação dos professores, no caso, a Educação Inclusiva, porém sempre atrelada à diversidade social com a qual se depara:

[...] Tal busca caracteriza-se e orienta a importância da formação continuada, principalmente quando surgem novas situações na prática do dia-a-dia. Por fim, um último momento trata-se da importância de nos depararmos com as discussões de inclusão na própria formação inicial, tornando, assim, possível a garantia de um profissional capacitado e ciente de que sua sala de aula é repleta de uma diversidade inimaginável. (p.25)

As Oficinas IN foram realizadas segundo a metodologia de ação em que os estudantes INgressos (com identificação protegida no preenchimento dos formulários no Registro Geral na entrada na universidade sob autorização ética pelo Termo de Consentimento Livre e Esclarecido - TCLE) foram convidados a adesão voluntária a participar da Oficina IN. A sistematização era a de envio de Convites aos estudantes INgressos pelo aplicativo on-line da universidade com explicações sobre objetivo, metodologia e público alvo.

Igualmente, era elaborado grupos de whatsapp das Oficinas IN com solicitação de preenchimento de formulário Google Docs pelo aplicativo da universidade para composição do grupo da Oficina IN. No preenchimento do Google docs teve adesão de 30 estudantes IN conforme oportunidade de divulgação e alcance dessa medida por todos os integrantes da Equipe IN.

Assim, o presente estudo possui por objetivo relatar a experiência do desenvolvimento das Oficinas IN considerando a análise dos impactos destas atividades no cotidiano dos estudantes, a operacionalização do ensino no ano de 2020 e considerando-se, os efeitos da pandemia na realidade dos estudantes ingressos da Universidade e os impactos da realização das oficinas como estratégia para permanência destes atores no âmbito da Universidade.

\section{Metodologia Relação Dialógica e Qualitativa da Oficina IN}

O presente estudo formula-se como um relato de experiência das atividades desenvolvidas pelas Oficinas IN, em modo remoto, considerando o ano de 2020. Realizou-se a descrição do perfil psicossocial dos estudantes participantes das atividades, considerando $n=62$ participantes ao longo do processo de encontros semanais e análise de vivências por meio da Análise de Conteúdo de Bardin. Em todo o processo de construção de categorias, procurou-se preservar trechos da fala expressa 
dos estudantes, e em seguida, pela inferência e interpretação ir além da apresentação linear, sugere Bardin (2011, p. 137).

Configurou-se na problematização argumentativa de tornar expressões e falas dos estudantes em argumentos significativos e válidos mediante leitura exaustiva do material, orientando-se por diversos polos de atenção, sempre dentro da temática IN na relação dialógica da comunicação.

Segundo Calixto-Flores (2020) a rota metodológica de desenvolvimento da investigação favorece apreciação das pessoas incluídas na metodologia indutiva-dedutiva, sendo esta realidade dinâmica e diversificada. Em uma perspectiva psicossocial, a metodologia da Oficina possui particularidades como guia técnico a ser seguido em atenção ao seu manejo e coordenação, conforme destaca Luiz, G. M. et al. (2014):

"favorece agir sob dois grandes eixos para a realização da oficina de dinâmica de grupo: o momento que antecede (demanda, pré-análise, foco e enquadre, e planejamento flexível) e o desenvolvimento propriamente dito (o aquecimento, a reflexão e a elaboração do tema, a sistematização e avaliação do trabalho)" (p.259).

Nas oficinas, a partir da definição de temas e discussão entre os participantes, foi discorrido de modo livre a oportunização de diálogos entre os estudantes, na identificação de similaridades de conteúdo e desenvolvimento de estratégias em comum.

\section{Resultados da Oficina IN Virtual Dialógica}

\subsection{Recorte Dialógico dos Estudantes Participantes nos Formulários de Inscrição Virtual Oficina IN}

Em retrospectiva do projeto IN desde 2019, no registro de inscrição acadêmico em 2020, o estudante foi convidado a preencher formulário de identifiçção de suas condições psicossociais. Como modo de afiliação à Oficina IN virtual, solicitou-se preenchimento de dados educacionais e garantia do sigilo ético em termo de comprometimento livre e esclarecido (TCLE) incluso. Na análise destes formulários de inscrição das Oficinas, obteve-se um recorte dos participantes considerando forma de ingresso na Universidade e configuração da rede social de suporte, na perspectiva do estudante.

Dentre a configuração identitária dos 30 estudantes IN participantes, obteve-se $60 \%$ integrantes da concorrência geral, no gráfico da forma de (IN)gresso a universidade, apresentada abaixo.

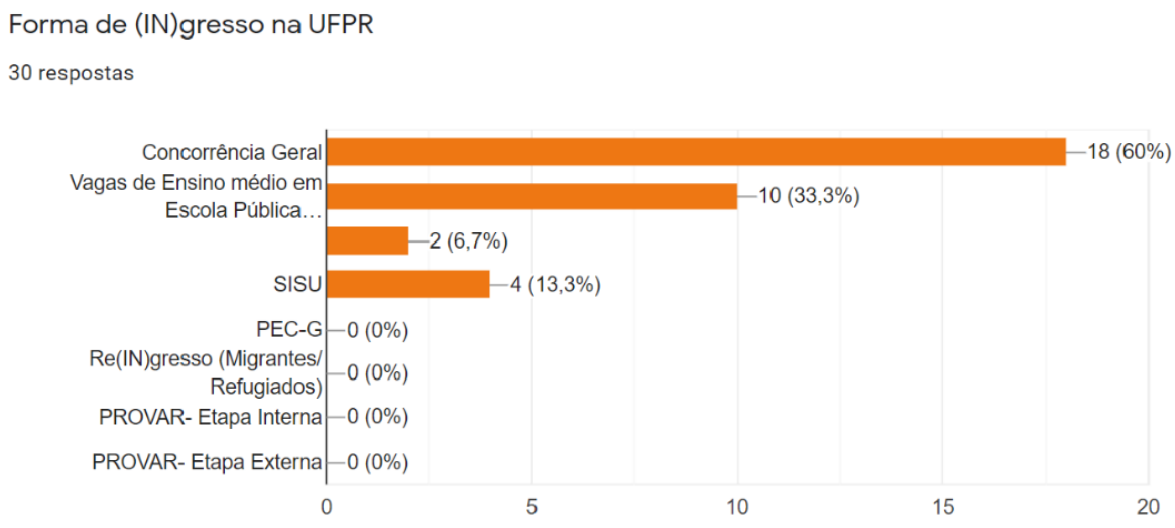

Fig. 1. Forma de ingresso dos estudantes do ensino superior 
E quanto a rede de apoio no universo relacional dos estudantes IN, é mencionado a figura materna, seguida da dos amigos, sobre a busca por conversa ou sentido de "poder contar" em relação social estabelecida, identificada no gráfico a seguir:

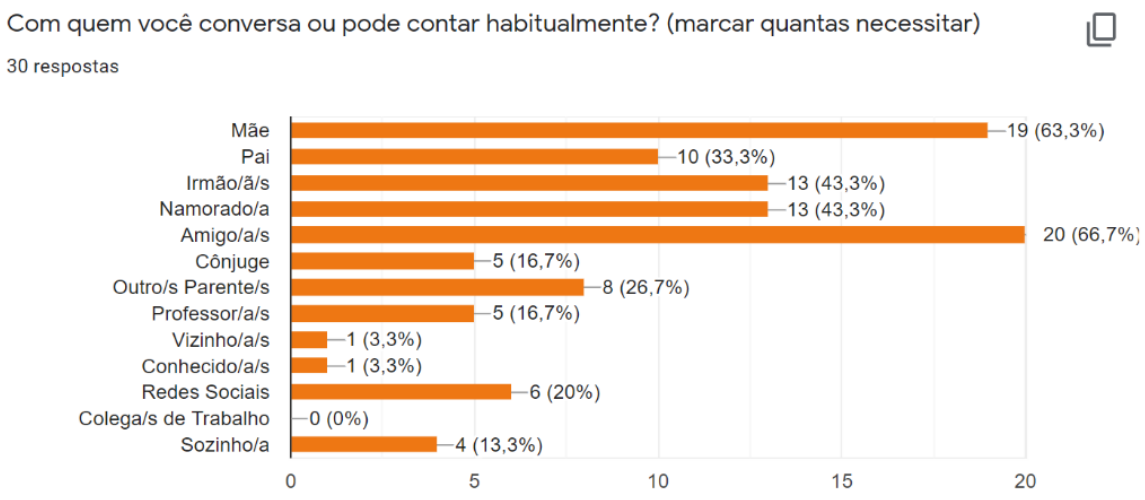

Fig. 2. Rede de apoio dos estudantes do ensino superior

O objetivo da atividade grupal se focalizou numa questão central (IN) enquanto debate de temáticas que o grupo se propõe a elaborar em um contexto social, propiciando aos estudantes espaços de construção do conhecimento e de participação ativa em suas ações. Metodologia da Oficina psicossocial em debate de temáticas mediante fragmentos de vida e da realidade pessoal/acadêmica dos participantes. Uma relação dialógica ou roda de conversa circular mediada por profissional psicólogo e estudante extensionista ancorados na participação voluntária, condição ética subjacente. Chamado ao público-alvo de todo estudante (IN)gresso à universidade pública federal, calouros dos cursos de graduação e de ensino profissionalizante.

\subsection{Metodologia de Análise de Conteúdo nos Diários de Campo}

Ao longo do projeto de extensão no ano de 2020 sucedeu 32 encontros dentre 437 chamados/convites, atingindo a participação de 62 estudantes INgressos que foram enumerados em grade de registro individual de cada um dos encontros, em número de convites e número de presenças, indicativo de $14,18 \%$ dentre os convites elaborados para este fim. O que sobressai todavia é a relação dialógica estabelecida, resultando em significativos desenvolvimentos peculiares ao contexto educacional vivenciado pelos estudantes. Cuesta-Benjumea (2011) destaca a interatividade reflexiva em todas as fases da investigação qualitativa:
En efecto, el proceso reflexivo impregna todos los niveles de un estudio de investigación, desde su orientación teórica a las reacciones de los participantes a la investigación. También está presente en todas las fases desde la pregunta de investigación al trabajo de campo, del análisis de los datos a la elaboración final del informe. (p.5)

O momento dialógico da Oficina IN se apresentou, em nosso entender, como uma experiência de conversa natural, fluida e de senso de confiança e compartilhamento social que tornava a relação de interesse mútuo e/ou interativa, em alguma medida. Diante desse cenário, fica o desafio de reflexão sobre as implicações para a inserção de pessoas na comunidade, quando as convicções de parte da sociedade têm estranhamento ao novo, ao não-familiar. O passo metodológico em todas as oficinas consistiu em três momentos: aquecimento, reflexão e elaboração dos temas emergidos e sistematização das idéias propostas. 
As Oficinas foram desenvolvidas com base em metodologia da hermenêuticadialética onde foi possível o processo reflexivo e trocas de experiências e reflexões entre os participantes e também com a equipe do projeto.

Este processo de interação pretendeu potencializar um processo transformador e educativo onde os atores envolvidos poderão desenvolver recursos e estratégias de enfrentamento frente as dificuldades ligadas a vida universitária, ou que interferem diretamente com a permanência do estudante. A circularidade comunicacional dialógica esteve presente na interação proposta do Projeto IN e na operacionalização da Oficina IN. Sidi, P. M. e Conte, E. (2017) remetem a contextualização e importância da relação dialógica e interativa em todo o processo relacional:

O círculo hermenêutico significa que não se pode conceber a compreensão fora de um contexto histórico e social. A circularidade da compreensão constitui-se a partir da relação e da condição de ser capaz de comunicar o seu conhecimento, de partilhá-lo, integrando a dialética intersubjetiva, que exige reciprocidade e intercomunicação. Compreender equivaleria então a ver e comunicar melhor, remete à interdependência constitutiva do todo e das partes e à impossibilidade da compreensão por dedução (p.1951-10952).

$\mathrm{Na}$ singularidade do público-alvo deste projeto (estudantes ingressos da UFPR), observa-se que tal metodologia pode favorecer a ampliação de repertório objetivo (conhecimento) e subjetivo (ligado a singularidade do sujeito) possibilitando 0 desenvolvimento de estratégias de cunho pessoal e social, com foco na permanência na Universidade.

Observamos a tenuidade de publicações na área num estudo qualitativo da pósgraduação ao concluir na opção inferior dos investigadores pela metodologia qualitativa em comparação à quantitativa (Antunes, A. 2018):

"análise e a discussão dos dados recolhidos permitem verificar que a metodologia qualitativa é reconhecida como forma de fazer ciência, no entanto o espaço que lhe é reservado é ainda bastante inferior ao assumido pela metodologia quantitativa. De facto, apenas cerca de $20 \%$ (14 dissertações num total de 68) dos trabalhos de investigação realizados recorreram a métodos qualitativos " (p.643-644).

Assim, em avaliação qualitativa conforme a leitura exaustiva do material registrado no Diário de Campo elaboradas pelos bolsistas extensionistas, obteve-se as Categorias de Análise de Conteúdo com depoimentos ilustrativos dos estudantes IN em destaque. *o grifo é nosso:

a. Sentimentos de vulnerabilidade e características ou conexões pessoais. Como lidar com o emocional, a vulnerabilidade? Importante participação de veteranos ao falar de história. No diário de campo da bolsista extensionista.

"Participação muito intensa de todos os estudantes, foi a que mais teve participação. As regras de participação foram bastante adotadas, toda hora tinha alguém com o braço ou a mãozinha levantada do aplicativo. Tanto quantidade na adesão quanto a qualidade do que era exposto foi muito evidente, a ponto de que a oficina parecia não ter fim, não querer acabar, já era quase mais de 2 horas de tempo final. Os temas foram muito variados e com descontração entre os estudantes. Todos os estudantes optaram por estar com câmara ligada e havia perguntas entre os próprios estudantes, algo não ocorrido anteriormente."

Sobressai a procura em lidar com as dificuldades quanto ao período de sono, rotina comprometida, relação com alimentação. Expressam detalhes em "você não vai conseguir", a percepção da diferença de realidade, sentimentos de frustração, angústia, sensação de falta de controle, preocupação, distração, falta de motivação. O sentir-se "perdida" no banho de lama junto com amiga, sem amigos no universo do estudante ingressante. 
b. O senso de pertencimento, o como fazer parte da universidade. Não sendo atividade presencial foram feitas sugestões de links ou ampliações de comunicações entre os participantes, debate sobre competitividade.

"Diz que "fica abstrato... final do ano ter festa com pessoas, confraternização gera pertencimento. Ter comunhão entre os cursos seria menos evasão. Me sentia mais parte do projeto de extensão do que do curso". "Identificação com o curso, fazer parte de centro acadêmico (c.a)... mas inclusão se dá no lado humano. São pessoas que falam com você, interagem com você, não é institucional. Tenho 2 colegas, um largou do ensino médio, outro está continuando. Acho que é mesmo estrutural, familiar e contexto econômico. A diferença de largar escola foi conexão, um ficou isolado, sozinho. Porque é gostar de ir para aulas, gostar de amigos. Peso humano é fundamental. Por mais estrutura que tenha a universidade, é o conectar, é a conexão com os pares é fundamental." (Oficina nํ-30 Manhã, estudante IN curso Letras)

É perceptível a explicação de instâncias na universidade, a necessidade de se ter voz ativa, realização de sonho. A busca de realização permeia conversa, debate sobre como trajetórias de encontrar-se com si mesmo por vezes demandam tempo.

c. Quanto aos Estudos/metodologia virtual na universidade surgem depoimentos, debates e vivências diferentes em que se tem questões em comum de falta de perspectiva do futuro. Como vai ser e como se afetar?

"Questiona-se quanto a ritmos e multiplicidade, propósito e sentido no curso. Diz "não é fazer por fazer, é o que fazer na vida". Agora no EaD uma demanda é como produzir uma vídeo-aula, buscar conhecimento que se tenha relevância social? Extrapolar para diversas abordagens extensionistas com objetivos práticos de realização, praticar, aplicar, sentir-se produzindo algo. É construir algo, é engajamento, fazendo, por ex, ensinar para estrangeiros, treinar didática. A forma como se recebe educação acaba tendo imagem da universidade. Quantos viram um tipo de valor, um desperdício de dinheiro público? Estou sendo mais produtivo, tô contribuindo um pouco mais". (Oficina nํ23 Tarde, estudante IN curso Direito)

Abordam-se inúmeros questionamentos e preferências pelo estudo, o sentido da metodologia de aula EAD funcionar ou não. Sobressaem questionamentos da avaliação metodológica na universidade, a relação virtual versus presencial quanto a contatos com os professores, menção sobre desempenho dos professores, obstáculos com internet, organização das turmas, motivação e expectativas, dentre outras.

Durante a sistematização da Oficina IN, solicitava-se aos integrantes da Oficina IN uma palavra final significativa da situação vivenciada, tendo sido observados nos registros dos diários de campo, sendo apontadas dentre elas, (conforto; acolhida; ajuda; iniciativa; conversa; alegria) equiparando-se a acolhimento, protagonismo e bem-estar vivenciado na experiência interativa.

Indagamos as questões da presença estar interligada aos cursos de humanidades como um diferencial e notadamente, a atuação ser ponto de destaque no interesse despertado no debate e colaboração dialógica na atividade desenvolvida, aliado ao destaque de duração da oficina de 1 hora e meia foi integralmente atingido, extrapolando em ocasiões.

\section{Conclusões}

A pandemia representou no cenário educacional um desafio para mudanças de paradigmas para a construção do conhecimento e modificação nos espaços relacionais, necessitando compreender o território virtual como algo também a ser construído, em relação ao senso de pertença. 
O Projeto IN na readaptação da metodologia de suas atividades enfrentou desafios ligados à sensibilidade do encontro virtual, que também contribuiu para a compreensão de outras vias de realidade em que o estudante está imerso, conhecendo seu cotidiano mais profundamente, o qual agora está fundido na relação entre a vida acadêmica e pessoal ou domiciliar. Dias-Bazo (2018) refere a complexidade e relevância da singularidade da investigação qualitativa:

Además, en la investigación cualitativa, las situaciones estudiadas son únicas e irrepetibles, no generalizables; por ello se espera que los significados, las interpretaciones y las inferencias particularizadas del estudio puedan transferirse a otro contexto o situación similar (transferibilidad), dar cuenta de la diversidad de experiencias (dependencia) y mostrar la neutralidad de la data (confirmación). Todo ello es posible a través de (1) la búsqueda de casos negativos o contradictorios que muestren la diversidad, contradicciones 0 tensiones de la data recogida; (2) la descripción detallada del tiempo, contexto y los sujetos; (3) la descripción detallada del proceso de investigación para dar pistas de revisión, y (4) la presentación de evidencias para la auditoría. (p. 794)

A oportunidade de favorecer espaços de troca e acolhimento entre pares mostrou-se viável também de modo remoto, contudo observa-se que o coordenador destes espaços de encontro deve estar atento e promover ações que favoreçam que os elos de sentimentos entre os integrantes do grupo se tornem também potências para as práticas. Quanto a análise reflexiva qualitativa, Diaz-Baso (2018) argumenta sobre a responsabilidade processual nos achados e representação das distintas vozes e representações da realidade percebidas. Mudanças cotidianas são possíveis no concreto do fazer rotineiro, mesmo que de modo virtual, podendo amplia foco dos contextos de interação que se quer identificar ou conhecer na realidade.

Assim, percebe-se que as Oficinas IN virtuais favoreceram este elo em um processo grupal lúdico e livre, oportunizando momentos em que os sujeitos estão em sincronia, formando novas redes sociais de suporte e fortalecendo as já existentes, na análise pessoal de suas potencialidades. Em última instância verifica-se que este recurso se configura como um agente de inclusão e permanência destes estudantes, objetivo final da assistência estudantil.

É a imensa instigação posta quanto a adesão da multiplicidade dos atores sociais na problematização da educação no território ecológico do ensino superior. Equivale refletir quanto a mobilização de subjetividades menos habituadas a este ato de falar/refletir/fazer na construção de paradigmas renovados conectado ao processo de vivência na universidade e em medidas de enfrentamento pessoal/social à pandemia.

Salientamos portanto, o grande desafio em tornar a política pública acessível a todos os estudantes, que seja consonante a participação ativa pela via de graduação em formulação de objetivos pedagógicos ou acadêmicos atrelado às vivências subjetivas emocionais no cotidiano universitário. Ainda fazemos questionamentos intricados como o de como transpor estes limites, se é que são tão evidentes e perceptíveis na esfera educacional, institucional? Muito embora haja conexões e embates frutíferos na produção do conhecimento em permanência no ensino superior sob uma ótica comunicativa de reciprocidade, resvala-se sobremaneira na dimensão de rendimento e produtividade preponderante no meio acadêmico.

Ponderamos quanto a necessidade de um olhar devido ao processo vivenciado pelo estudante ingresso (IN) na universidade, considerando a múltipla diversidade na inclusão de estudantes no ensino superior público. 


\section{Agradecimentos}

O projeto IN agradece a oportunidade de inscrição ao sistema de seleção de bolsas de extensão da Pró-Reitoria desta ordem, havendo a possibilidade de engajamento dos estudantes e ampliação vital das ações via inclusão dos estudantes bolsistas extensionistas.

\section{Referências}

Antunes, A. P. (2018) Investigação qualitativa em Psicologia: Dados e evidência num curso de mestrado. Atas CIAIQ2018, Investigação Qualitativa em Educação, Investigación Cualitativa en Educación, Volume 1.

Bardin, L. (2011) Análise de Conteúdo. São Paulo: Edições 70.

Calixto-Flores, R. (2020) El sentido de las prácticas eductivas en educación ambiental. Universidad Pedagógica Nacional, México. Investigación Qualitativa en Educación: Avances y Desafios. DOI: https://doi.org/10.36367/ntqr.2.2020.1-12.

Cruz, J. P. D. Cruz \& Abade, F. L. (2014) Intervenção psicossocial com Oficinas em dinâmica de Grupo: reflexões sobre o fazer com grupos de crianças e de adolescentes.

Cuesta-Benjumea, C. de la (2010) La Reflexividad: un asunto crítico en la investigación cualitativa. Departamento de Psicología de la Salud. Universidad de Alicante (España). IV Congreso Iberoamericano de Investigación Cualitativa, Fortaleza, Brasil.

Díaz-Camargo, E., Riaño-Garzón M., García, S. A. B., Vallejo D. Y. M., Méndez L. I. S., Valero, I. Y. \& Bautista-Sandoval, M. J. (2020) Acompañamiento Psicológico y Permanencia en Estudiantes universitários. Psicologia Escolar e Educacional, v. 24

Diaz-Bazo, C. (2028) Los criterios y estrategias de calidad: lo invisible en la publicación de las investigaciones cualitativas. Departamento Académico de Educación, Pontificia Universidad Católica del Perú. Atas CIAIQ2018, Investigação Qualitativa em Educação, Investigación Cualitativa en Educación, Volume 1.

Luiz, G. M., Dal Prá, R. M. \& Azevedo R. C. (2014) Intervenção psicossocial por meio de oficina de dinâmica de grupo em uma instituição: relato de experiência. Psic. Rev. São Paulo, volume 23, n.2, 245-260.

Oliveira, M. L., Antunes, A. M,, Rocha, T. L. \& Teixeira, S. M. (2011) Educação Inclusiva e a Formação de Professores de Ciências: o papel das universidades federais na capacitação dos futuros educadores. Rev. Ensaio, Belo Horizonte, v.13, n.03, p.99117.

Santana, R. O., Mól G. S. \& Silva, W. P. (2018) Educação Inclusiva: Desafios encontrados por um grupo de professores e suas especificidades no fazer pedagógico. Atas CIAIQ2018, Investigação Qualitativa em Educação, Investigación Cualitativa en Educación, Volume 1.

Sidi, P. M. \& Conte E. (2017) A hermenêutica como possibilidade metodológica à pesquisa em educação.RIAEE - Revista Ibero-Americana de Estudos em Educação, Araraquara, v.12, n.4 , p. 1942-1954. E-ISSN: 1982-5587. 